\title{
LA PROPUESTA
}

AGRARIA DE

VENUSTIANO

CARRANZA Y LOS

SONORENSES

(1915-1929)*

Marta García Ugarte**

$\mathcal{H}_{1}$ estudio de la legislación agraria emitida durante los gobiernos de Venustiano Carranza y los sonorenses Álvaro Obregón y Plutarco Elías Calles (1917-1929) muestra que el proyecto de fraccionar las haciendas, o de modificar la estructura de la tenencia de la tierra en México, estuvo sujeto a modificaciones radicales según las presiones sociales (políticas, económicas y militares) propias del momento histórico que se tratare. En cambio, el proyecto de modernización de la producción agrícola elaborado en la última etapa del porfiriato (1904) prácticamente se mantuvo estable hasta la época del general Calles y Cárdenas.

Es de destacar que tanto el Porfirio Díaz de 1904, como Obregón, Calles y Cárdenas, concentraron su atención en fortalecer la agricultura capitalista de exportación. Es decir, aquella que, por la situación económica de los propietarios y la calidad del suelo, podía introducir innovaciones tecnológicas que permitieran incrementar la productividad. Por otra parte, la mayoría de los sectores sociales involucrados en la definición de la política

* Trabajo presentado en la Conferencia Anual (No. 37) de la Western Social Science Association, Land Grand Section, celebrada en Oakland (CA), Estados Unidos, del 26 al 29 de abril de 1995.

** Departamento Académico de Estudios Generales, ITAM. 


\section{MARTA GARCÍA UGARTE}

agrícola gubernamental coincidían en las estrategias y objetivos necesarios para impulsar el desarrollo económico del sector agropecuario.

Las diferencias notables se registraron en torno al principio, sostenido por algunos, de que era imposible impulsar el desarrollo de la agricultura si antes no se efectuaba una transformación radical de la tenencia de la tierra: la hacienda era, se aseguraba, improductiva. Así, antes de que se iniciara el movimiento político de Francisco I. Madero en 1910, la Secretaría de Fomento porfirista empezó a reconocer la necesidad de crear la pequeña propiedad o propiedad de familias. Se debatía entonces la forma de llevar a cabo esa transformación puesto que se esperaban resistencias, explicables, de los grandes propietarios. Las opiniones se dividieron una vez más en torno a la forma de lograr ese fraccionamiento: violenta o moderada.

En ese punto de la discusión, se desencadenaron los hechos revolucionarios que llevaron a Francisco I. Madero a la presidencia de la República. Acontecimientos que pusieron, aún cuando Madero se encontraba distante de un proyecto agrario radical, las demandas de los viejos pueblos indios, que encabezaba Emiliano Zapata, de lograr la restitución de las tierras de sus mayores que habían sido usurpadas por las haciendas. Demanda que se tradujo, en oposición a Madero, en el Plan de Ayala de 1912.

32 Entonces, se retomó el debate agrario que había quedado suspendido en el tiempo. Manuel Bonilla, quien accedió a la dirección de la Secretaría de Fomento en el último trimestre de 1912, asumió la propuesta porfirista de "avanzada": impulsar la pequeña propiedad a través del sistema de "producción familiar" y fomentar un fraccionamiento natural del latifundio mediante políticas arancelarias y productivas que condujeran a la baja el valor de la propiedad raíz. Pero este programa se quedó en suspenso porque, como comenta Fernando González Roa, "se escucharon los primeros cañonazos de la ciudadela". Es decir, la revuelta encabezada por Victoriano Huerta, conocida como decena trágica, que culminó con los asesinatos de Madero y Pino Suárez.

El gobernador de Coahuila, Venustiano Carranza, emitió el Plan de Guadalupe, el 6 de marzo de 1913, que desconocía al presidente usurpa-

${ }^{1}$ Fernando González Roa, El aspecto agrario de la Revolución Mexicana, 1919, México, Poder Ejecutivo Federal, Departamento de Aprovisionamientos Generales, Dirección de Talleres Gráficos, p. 229. 


\section{PROPUESTA AGRARIA DE VENUSTIANO CARRANZA}

dor y a cualquier otro que proviniera del cuartelazo de febrero, y también a los gobiernos estatales que hubieran aceptado su dominio: la Revolución, en su etapa constitucionalista, se había iniciado. En su proceso, el proyecto agrario porfirista entroncaría con el proyecto de restitución de tierras de Emiliano Zapata, y también con la Ley del 6 de enero de 1915 de Venustiano Carranza y la emitida por Francisco Villa.

Antes de entrar en materia, cabe señalar que los proyectos agrarios revolucionarios, y después las legislaciones de los sonorenses y la cardenista, de cobertura nacional, tuvieron un efecto diferente en las entidades federativas. Efectos que, por otra parte, permiten sopesar más objetivamente las pretensiones y propósitos del proyecto agrario mexicano. En esa razón, este trabajo sigue la forma como la legislación agraria se fue entretejiendo con las vicisitudes políticas nacionales y la estructura socio-económica del estado de Querétaro.

\section{Las propuestas agrarias revolucionarias}

En Querétaro no se tenía ninguna intención de fraccionar las haciendas. Esta afirmación es válida aún cuando el hacendado Julián Malo Juvera, quien se había sumado a las filas constitucionalistas en 1914 y al villismo en 1915, había publicado en enero de 1915 un "Proyecto de ley para el fraccionamiento de terrenos". En honor de Malo Juvera, ése fue el único documento agrario queretano antes de 1923 que postulaba el fraccionamiento de la hacienda. Malo Juvera, entonces villista, proponía una expropiación en base al valor que el propietario otorgara a sus terrenos y una "venta" de los lotes a todos los mexicanos "honrados y laboriosos". En su propuesta el fraccionamiento de las haciendas sería un negocio particular, ya fuera que estuviera en manos de los dueños de los terrenos o de compañías formadas ex-profeso para el fraccionamiento. ${ }^{2}$

El proyecto de Malo Juvera, de claras reminiscencias porfiristas, no ejerció influencia alguna en la entidad. Tampoco tuvo impacto la Ley de dotaciones y restituciones del 6 de enero de 1915 emitida por Venustiano

2 Julián Malo Juvera, "Proyecto de ley para el fraccionamiento de terrenos", 1 de enero de 1915, en Marte R. Gómez, La reforma agraria en las filas villistas. Años 1913 a 1915 y 1920, 1966, México, Instituto Nacional de Estudios Historicos de la Revolución Mexicana, p. 224-34. 


\section{MARTA GARCÍA UGARTE}

Carranza ni circuló, por el control político-social que ejercían los hacendados, el Plan de Ayala de Emiliano Zapata. Ciertamente, en Querétaro no había un ambiente favorable a la reforma agraria ni se distribuía información al respecto, puesto que nadie estaba interesado en despertar la "avaricia" de los pueblos indios y los pueblos libres de la entidad que, desde el al menos siglo XIX reiteradamente habían reclamado la devolución de los terrenos que habían sido usurpados por las haciendas. También es cierto que la Comisión Local Agraria, órgano que había sido establecido por la Ley del 6 de enero de 1915 para encargarse de atender las solicitudes de restitución y dotación, sólo había funcionado algunos días debido a la inestabilidad política y militar de ese año. Así, ningún pueblo de Querétăro se acogió a los beneficios de la ley.

No obstante, una vez reinstalada la Comisión Local Agraria en 1916, una vez que los carrancistas ocuparon la plaza de Querétaro que había sido tomada por los villistas, de inmediato tres pueblos se acogieron a la ley del 6 de enero de 1915: Santa Rosa de Jáuregui, pueblo libre de la entidad, y los pueblos Hñahñú, Santiago Mezquititlán del distrito de Amealco, y el barrio de La Magdalena de la municipalidad de Tequisquiapan del distrito de San Juan del Río.

Pero entonces, se había decidido no poner trabas al desarrollo agrícola de los hacendados de Querétaro, estado que se había convertido en uno de los graneros del gobierno que encabezaba Venustiano Carranza. ${ }^{3}$ En ese propósito, y con el deseo de evitar que otros pueblos solicitaran demandas de restitución, los tres poblados enfrentaron el mismo dictamen: según el perito evaluador, los documentos presentados para hacer valer los derechos de propiedad de los pueblos eran "apócrifos pues ni por su aspecto, ni por el papel en que están escritos, letra de ellos y la fecha en que aparecen otorgados merecen ningún crédito respecto a su autenticidad".

En el bienio 1916-1917, tanto las autoridades militares (carrancistas) como los hacendados de Querétaro temían que se despertara el viejo

${ }^{3}$ De hecho, Venustiano Carranza había dispuesto, en 1916, que no se procediera al reparto de la tierra. Romana Falcón reseña que, "a principios de 1916, Carranza prohibió a las autoridades agrarias estatales alterar o reglamentar la Ley del 6 de enero de 1915...mientras enfatizó que, como la reforma a la propiedad rural estaba en su primera fase, aún no se procedería a distribuir la tierra". Romana Falcón, Revolución y caciquismo. San Luis Potosí, 1910-1938, México, El Colegio de México, 1984, p. 141. 


\section{PROPUESTA AGRARIA DE VENUSTIANO CARRANZA}

anhelo indígena de recuperar las tierras usurpadas por las haciendas, tanto desde tiempos "inmemoriales" como durante la década 1870-1880 cuando los hacendados habían extendido los límites territoriales de sus propiedades a fin de acaparar el recurso agua. ${ }^{4} \mathrm{De}$ ahí que los miembros de la Junta Local Agraria, coaligados con el grupo de los hacendados, aceptaran que los títulos de propiedad presentados en 1916 eran falsos.

Sorpresivamente, los habitantes de la cabecera distrital villa de Colón pidieron dotación de tierras en ese mismo año. En ese entonces, 1916, la villa de Colón tenía 624 jefes de familia que podían ser dotados. Algunos de ellos eran propietarios de "lotes" dedicados a la agricultura y otros se dedicaban la compra-venta de ganado. Es decir, se trataba de una comunidad de rancheros, próspera como otras de la entidad, que mantenía vínculos con las haciendas comarcanas. Los dueños de las haciendas que podían ser afectadas, Pedro Gorozpe, el propietario de la hacienda de Ajuchitlán y sus anexas, El Rosario y Panales, y el del rancho Santa María de Guadalupe o El Mexicano, alegaron en su defensa que los habitantes de Colón no podían solicitar dotación de tierras porque no tenía la categoría política que había determinado la Ley del 6 de enero de 1915, es decir, no se trataba de una población de escasos recursos. Además, las susodichas fincas ya habían sido fraccionadas.

Es claro que se quiso impedir que la solicitud de los rancheros de la villa de Colón prosperara, puesto que bajo su ejemplo se corría el riesgo de que todos aquellos individuos que habían sido dotados de tierras por las leyes liberales de mediados del siglo XIX también hicieran solicitudes de dotación para ampliar sus ranchos. Y era muy difícil rechazar esas solicitudes porque los dotados por las leyes liberales se habían asentado en poblaciones nuevas, "libres". Es decir, sus viviendas no se localizaban en terrenos que eran propiedad de las haciendas como pasaba con muchas rancherías o lugar de asiento de los peones y medieros de las fincas rústicas. Por esa independencia, y según la Ley del 6 de enero de 1915 , podían ser dotados. En tal situación estaban los pobladores de El Sitio, Corral Blanco (años más tarde denominada Ezequiel Montes), Arroyo Seco (en 1904 denominada Pedro Escobedo) y Concá, situado a la vera de la hacienda San Nicolás Concá.

${ }^{4}$ Cfr. Marta Eugenia García Ugarte, Hacendados y rancheros queretanos (1780-1920), 1992, México, Consejo Nacional para la Cultura y las Artes. 


\section{MARTA GARCÍA UGARTE}

La fuerza económica que disfrutaban estas sociedades de rancheros y los vínculos que sostenían con las haciendas, puesto que fungían como medieros, administradores, mayordomos "mandones" y hasta de peones de las fincas rústicas podía empujarlos, si observaban que había una vía institucional para lograrlo, a demandar las tierras de las haciendas que trabajaban como medieros o arrendadores, que generalmente, colindaban con sus fajas y labores de tierra. Era previsible además que si los rancheros ampliaban los límites de sus propiedades, las haciendas perderían no sólo parte de sus terrenos sino también una fuerza de trabajo, la más importante, puesto que los propietarios asumirían los puestos administrativos.

No obstante, los rancheros tardaron en organizar sus peticiones de tierras porque no conformaban un grupo unificado. Además, la Junta Local Agraria de 1916 se desintegró ese mismo año porque todos los miembros que la constituían -elementos de la clase media urbanarenunciaron el 21 de junio de 1916 . En apariencia, esa renuncia masiva se debió a que nadie quería ser parte de un organismo que entraba en contradicción abierta con el poderoso grupo de los hacendados. Así, de 1911 a 1917 en el estado de Querétaro nada se había hecho en materia agraria.

Aún después de emitida la Constitución de 1917, la del país y la local, las solicitudes de tierras seguían siendo de restitución (once en sólo

36 cuatro meses) y solamente se presentó una de dotación. Todas ellas rechazadas en 1919, con excepción de la petición de Santa Rosa de Jáuregui, porque Pastor Rouaix, secretario de Agricultura y Fomento, había asentado, en una circular del 21 de marzo de 1918, que no obstante que era "urgente" proveer de tierras para sembrar a los labradores pobres, ese reparto no era posible "por ahora", hasta que no se contara con la ley reglamentaria del artículo 27 constitucional. Sólo se podían otorgar tierras de acuerdo a la Ley del 27 de noviembre de 1896 y su respectivo reglamento del 6 de septiembre de 1897, que ordenaba el reparto individual de las tierras comunales y reconocía como labradores pobres aquellos cuyas propiedades valieran $\$ 200.00$. La misma que había sido duramente criticada por Andrés Molina Enríquez en su conocida obra Los grandes problemas nacionales, porque era prácticamente imposible "medir" terrenos tan pequeños. Con esta disposición, el carrancismo iba en contra de las disposiciones de la Ley del 6 de enero de 1915 que había autorizado a las autoridades militares de cada lugar a efectuar 


\section{PROPUESTA AGRARIA DE VENUSTIANO CARRANZA}

"las expropiaciones que fueran indispensables" para dar tierras a los que carecían de ellas.

De manera independiente a las restricciones que existían en 1919, la petición del pueblo de Colón fue retomada. Entonces, se decidió dotar a solicitantes con 877 has. con terreno cerril y de mala calidad, que se tomaría de la hacienda El Lobo y sus anexas, que tenían una extensión de 36170 has. y de Ajuchitlán, que medía 20,000 has. ${ }^{5}$ De tal manera que las 556 has. que se quitarían al Lobo y las 312 que se tomarían de Ajuchitlán eran inferiores a las extensiones de los pejugales que entregaban los hacendados a los medieros como parte del salario que devengaban.

Mientras el pueblo de Colón recibía esa dotación irrisoria, la solicitud del Pueblito, antiguo pueblo novohispano, fue rechazada porque los solicitantes eran, decían los hacendados, propietarios prósperos que sólo estaban interesados en apropiarse de las tierras irrigadas que colindaban con sus terrenos. Además, la mayoría de las haciendas que podían ser afectadas (las de Tejeda, El Cerrito, La Negreta y Balvanera) se encontraban fuertemente endeudadas por créditos que habían invertido en infraestructura de riego. Así, para proteger la agricultura de esta microregión, fue rechazada esta solicitud. Además, en una interpretación de la ley del 6 de enero de 1915 y del artículo 27 constitucional que perduró hasta 1940, los integrantes de la Comisión Local Agraria asentaron que el propósito de las leyes agrarias no era "convertir en propietarios de tierra a todos los habitantes de los pequeños poblados de la República, máxime, cuando tales habitantes como en el presente (villa del Pueblito) constituyen un factor imprescindible de la producción en grande escala cuyo fundamento es tan necesario". 6 Principio que enarbolaban los hacendados, y que incluso en la cúspide del reparto agrario 1934-1937 tuvo que considerar el presidente Lázaro Cárdenas.

La razón por la que en 1919 se negó la restitución de tierras solicitadas por los pueblos otomí de Amealco expresa que se tenía claro, como en la última etapa del porfiriato, que la restitución de las tierras no resolvía el "problema angustioso de los pueblos". Para que la política agraria fuera efectiva era preciso que de manera simultánea se iniciaran las obras

${ }^{5}$ Diario Oficial del estado de Querétaro, La sombra de Arteaga, 17 de enero de 1920.

${ }^{6}$ Comisión Nacional Agraria, 31 de ocubre de 1919. Publicado en La sombra de Arteaga del 20 de diciembre de 1919. 


\section{MARTA GARCÍA UGARTE}

de riego, puesto que los vecinos de los pueblos indios "se conformaban" con el mísero salario que fluctuaba entre 12 y 25 centavos, para el cuartillo de maíz, porque sus tierras no producían lo suficiente para sostenerlos dado que eran de temporal y de mala calidad. También se sostuvo, en una contradicción con el planteamiento anterior, que todavía había suficiente tierra comunal para repartir a nivel individual. Se continuaba así la política agraria porfirista (reglamento de 1878) que había ordenado la titulación individual de los terrenos comunales. Bajo esas resoluciones, los habitantes de los pueblos de Colón, Boyé y San Pablo, desistieron de sus solicitudes.

La única dotación de tierras que se concedió en 1919, además de la restitución otorgada a Santa Rosa de Jáuregui, tuvo un origen político. Se trató de los habitantes del antiguo Arroyo Seco, el actual Pedro Escobedo, pequeños comerciantes que para mejorar sus ingresos habían solicitado las tierras de las haciendas comarcanas (El Ahorcado, San Clemente, El Sauz, La Lira y el rancho Arroyo Seco).

En este caso, los hacendados intervinieron directamente asegurando a los habitantes de Pedro Escobedo que de seguir con sus pretensiones agrarias, les quitarían el acceso a las aguas del Río San Juan que controlaban las mencionadas haciendas y nunca más volverían a ser ocupados (contratados) por las haciendas. Tal manifestación ponía en evidencia que el control del estado seguía estando en manos de los hacendados y no del poder político revolucionario. Incluso para los carrancistas, lejanos de los postulados agrarios, era inaceptable que un grupo de particulares se pusiera por encima de la jurisdicción gubernamental, como se desprendía de las declaraciones de los hacendados sanjuanenses. De ahí que se decretó que era procedente la dotación del pueblo de Pedro Escobedo porque "era un grupo explotado por las haciendas". En realidad no era así pero, ¿qué otra justificación podían escoger?

Es claro que los esfuerzos históricos de los pueblos indios y los rancheros en nada coincidían con las pretensiones locales y federales del carrancismo. Hasta 1920, las dos resoluciones favorables concedidas en el estado de Querétaro pueden considerarse simbólicas y representativas de una intención revolucionaria poco interesada en expresarse en cambios concretos en la tenencia de la tierra. Pese al artículo 27 constitucional, el gobierno federal, el de don Venustiano Carranza, carecía de un proyecto agrario. 
La falta de visión de los carrancistas, o su ceguera para medir la importancia que tenía para la estabilidad política y el desarrollo del país el fraccionamiento de los latifundios, la fundación de instituciones de crédito, la infraestructura para la producción (obras de ingeniería hidráulica, caminos) y el fortalecimiento de la educación de los productores rurales no es sorprendente. En todo caso, era una consecuencia de la situación del país, que demandaba todos los esfuerzos para lograr su pacificación. También reflejaba las diferencias que existían en torno a las formas, radical o violenta, de realizar el fraccionamiento de las haciendas y sobre el sistema de tenencia que se deseaba instrumentar: la pequeña propiedad en coexistencia pacífica con la gran propiedad, como era el proyecto porfirista de 1902, o la restitución y dotación de las tierras comunales a los pueblos como pretendía el Plan de Ayala de Emiliano Zapata que, aunque Luis Cabrera dice que no se conoció hasta el triunfo de la Revolución sobre el huertismo (en 1914), influyó para que se enfatizara la necesidad de convertir a los peones en colonos libres que cultivaran su propio campo con sus familias. También circulaba la Ley agraria de Villa que fundamentaba el fraccionamiento de los latifundios no en razón de la pequeña propiedad sino en cuanto superficie máxima de terreno que podía disponer un sólo dueño. Cantidad que sería delimitada en función del riego, la densidad de la población, la calidad de las tierras "y todos los demás elementos que sirvan para determinar el límite más allá del cual la propiedad llegara a constituir una amenaza para la estabilidad de las instituciones y para el equilibrio social". Los villistas aspiraban, como registrara Antonio Díaz Soto y Gama en 1959, "a la posesión de una unidad agrícola que mereciera el nombre de rancho y no a la parcela paupérrima del ejido". 7

Tales programas y propósitos estaban firmemente asentados en el México de la Revolución. En ese sentido, la inmovilidad de los carrancistas en materia agraria también se debía a que la política agraria se había dejado en manos de Pastor Rouaix quien, desde el triunfo maderista, había hecho suyo el proyecto porfirista más conservador. Por su parte, Manuel Bonilla, quien había sido Secretario de Fomento en el

${ }^{7}$ Antonio Díaz Soto y Gama, La cuestión agraria en México, 1959, México, Instituto de Investigaciones Sociales, Universidad Nacional Autónoma de México, p. 29. 


\section{MARTA GARCÍA UGARTE}

último trimestre de 1912, elaboró el proyecto de Ley Agraria del estado de Chihuahua, apegado a los principios porfiristas. Tanto es así, que Marte R. Gómez, quien elogiaba los méritos revolucionarios de Bonilla y su leältad al maderismo, reconocía que el agrarismo de don Manuel "era comedido" porque consideraba que expropiar era "incurrir en actos de violencia". 8

Bajo una u otra concepción, en 1920 todas las fuerzas revolucionarias y políticas del país reconocían que el problema agrario ameritaba una resolución rápida y expedita. Sin embargo, frente a la necesidad de estabilizar el país, el carrancismo parecía desconocer la "urgencia" de resolver la problemática del agro mexicano y tampoco demostraba interés en cambiar el régimen de la tenencia de la tierra ni siquiera en el sentido de la pequeña y mediana propiedad. En todo caso, después del Plan de Agua Prieta, que condujo al desastre el gobierno y la vida de Venustiano Carranza, se abrió camino la preocupación moral por las condiciones de los trabajadores rurales y por la explotación sistemática de los contratos de aparcería.

\section{La propuesta agraria y agrícola de los generales Álvaro Obregón y Plutarco Elías Calles}

Los diferentes documentos publicados sobre la explotación de los trabajadores rurales no alcanzaban a reflejar el derecho que tenía el patrón de utilizar la fuerza de trabajo del aparcero ni la serie de estipulaciones por las cuales, de una u otra manera, el mediero siempre salía perdiendo frente a la hacienda. Mucho menos reconocían que mientras existieran los contratos de aparcería (a medias, al quinto y al rajar) permanecerían idénticos los pilares que permitían la explotación de la gran propiedad. Condición que expresa que, en realidad, no se tenía ninguna intención de lesionar el sistema de la hacienda. De ahí que, lejos de instrumentar un proyecto agrario, se empezaron a emitir leyes reguladoras de la aparecería que dejaban intactos los factores laborales y productivos que sostenían el régimen de la gran propiedad.

Éste fue el caso de la Ley de tierras ociosas, publicada el 23 de junio de 1920 por Adolfo de la Huerta, presidente interino de la República al

${ }^{8}$ Marte R. Gómez, Op. cit. p. 106. 


\section{PROPUESTA AGRARIA DE VENUSTIIANO CARRANZA}

triunfo del Plan de Agua Prieta. Ley que, generalmente, ha sido identificada como una de las primeras disposiciones agrarias después del revolucionario artículo 27 . No obstante, la misma no tenía un propósito agrario sino productivo, puesto que obedecía a la intención de incrementar la productividad agrícola. Por otra parte, no disponía elementos novedosos para organización de la producción puesto que se fundamentaba en la aparcería que era el sistema tradicionalmente usado por la hacienda. Asimismo contenía el propósito político de otorgar una fuente de financiamiento a los municipios a fin de fundamentar su autonomía política.

También es cierto que Álvaro Obregón, como los otros dos sonorenses que encabezaron el Plan de Agua Prieta, Adolfo de la Huerta y Plutarco Elías Calles, consideraba que la reforma agraria debía encaminarse por la pequeña propiedad y que el fraccionamiento del latifundio debía realizarse ordenadamente y de acuerdo con los intereses económicos del país. Esa postura había sido clara en el discurso que sostuvo el general Obregón en la Cámara Agrícola del estado de Jalisco en el cual había condenado la improvisación y la falta de visión con que algunos generales estaban fraccionando el latifundio y destruyendo negociaciones agrícolas de importancia para el futuro económico del país.

Es claro que el gran proyecto del presidente era mejorar las condiciones técnicas de producción (la irrigación, el crédito, la organización de productores, el mejoramiento de las semillas y formas adecuadas de comercialización que incrementaran los ingresos del productor) y orientar la reforma por la pequeña propiedad. Era entonces, un programa de progreso agrícola y no de reforma agraria. Incluso el proyecto de Ley sobre el fraccionamiento de los latifundios presentado a las cámaras el 9 de febrero de 1921 "protegía" aquellas negociaciones agrícolas "que tuviesen establecidos sistemas modernos de cultivo".

No obstante, Obregón no podía dejar de satisfacer las demandas agrarias de los hombres del campo, porque ellos habían sido sus grandes aliados, junto a los obreros, cuando el Plan de Agua Prieta. Además, un programa agrario suave y bien dirigido restablecería la unidad revolucionaria que se había perdido con los acontecimientos de Tlaxcalaltongo, cuando perdió la vida el presidente Carranza. De ahí que el Reglamento agrario del 10 de abril de 1922 abrió las puertas para que los centros de población que no estaban situados en terrenos de las haciendas pudieran solicitar dotaciones de tierra. Es decir, podían solicitar tierras los grupos 


\section{MARTA GARCÍA UGARTE}

rancheros que se habían sumado al Plan de Agua Prieta quienes, por otra parte, habían sido armados por el gobierno federal.

Con fuerzas armadas propias y con una legislación favorable, los rancheros se atrevieron a solicitar las tierras que trabajaban a medias con la hacienda. Tal fue el caso de los rancheros de Concá, de la Sierra Gorda del lado queretano, quienes no sólo solicitaron las tierras de la hacienda de Conca sino que, amparados por las armas y porque ocupaban los puestos políticos del municipio y del poblado, las ocuparon antes de que se emitiera la resolución agraria. El proceso, iniciado en 1921, tardó cinco años en resolverse tanto por la renuencia regional como por la intervención de la Embajada norteamericana, dado que San Nicolás Concá estaba en propiedad de un ciudadano norteamericano, Alejandro S. Sharpton.

Es de señalar que excepto la de Concá, ninguna otra sociedad ranchera de la entidad se acogió a esta ley. La pasividad de los rancheros de los valles queretanos encuentra su explicación en las condiciones altamente productivas de esta región, donde desde el porfiriato se habían venido realizado fuertes inversiones en infraestructura de riego. De esa manera, los hacendados de los valles podían acogerse a las disposiciones del reglamento obregonista que protegía las unidades agrícolas productivas y las propiedades de los hacendados que no temían invertir en la adquisición de nueva tecnología. Propósito que determinó la decisión de poner candados al reglamento agrario a fin de que los peones y trabajadores de las fincas no pudieran pedir dotaciones con el propósito de "preservar" la fuerza de trabajo de las unidades agrícolas.

Por otra parte, el reglamento ponía fin a los repartos de tierras de mala calidad, que había sido una constante revolucionaria, a la vez que protegía la pequeña propiedad. Así, aún cuando establece el minifundio, éste variaba de tamaño según si se tenía o no posibilidad de riego. ${ }^{9}$

Así, se trataba de una reforma agraria moderada que no pretendía destruir la base agrícola que sostenía la hacienda. Se iban a repartir tierras ciertamente, pero sin atentar contra la industria agrícola y ganadera del país que era exitosa y la dotación se haría de manera gradual. Puede obser-

${ }^{9}$ La extensión de los ejidos era de tres a cinco hectáreas en los terrenos de humedad o de riego; de cuatro a seis en los terrenos de temporal con precipitación pluvial abundante y de seis a ocho en aquellas tierras de temporal de otras clases. Cantidades que podían aumentarse hasta el triple cuando se tratara de terrenos cerriles o áridos. 


\section{PROPUESTA AGRARIA DE VENUSTLANO CARRANZA}

varse que el general Obregón no tenía la intención de afectar de manera seria los grandes latifundios productivos. Pero, al mismo tiempo, se deseaba favorecer a la población rural que había sido, y seguía siendo, uno de los principales soportes de los gobiernos revolucionarios.

Las puertas que abrió el régimen de Obregón para una mejor organización del mundo rural no fueron aprovechadas por la dirigencia política queretana, todavía renuente a tocar una de las fuentes de trabajo más lucrativas de la entidad. La única petición agraria que cruza el período 1920 a 1925, la de los rancheros de Concá, se encuentra estrechamente relacionada con los afanes de poder de cada uno de los cinco gobernadores que se sucedieron de 1920 a 1925 , que necesitaron de las fuerzas armadas de los rancheros para sostener sus gobiernos. Pero ante todo, se debió a los alientos y aspiraciones de los rancheros armados, que por primera vez se encontraron en posibilidad de enfrentar el poder hegemónico que desde finales del siglo XIX ejercían los hermanos Olvera en la región serrana.

Es innegable que los dirigentes políticos queretanos, que provenían de la clase media y aristocrática, no tenían ninguna intención de fraccionar la hacienda. Tan sólo se preocuparon por mejorar las condiciones de trabajo de las fincas rústicas, disposiciones que en nada contribuían a modificar el régimen de la tenencia de la tierra. Esta posición quedó establecida en la reglamentación agrícola que contiene la Ley del trabajo que fue emitida en diciembre de 1922 por la XXV legislatura local que sólo regulaba las prácticas tradicionales que habían permitido la existencia de la hacienda: la mediería, las jornadas de trabajo, los salarios en especie.

Los acontecimientos políticos y militares de la última etapa del gobierno del general Obregón, por la "imposición" de la candidatura del general Plutarco Elías Calles, que desencadenaron la revuelta delahuertista, pusieron a discusión el proyecto de nación con la misma intensidad y ambigüedad que durante el proceso revolucionario. De 1923 a 1931, en que se sucedieron tres revoluciones (delahuertista, cristera y de Escobar) y se conformó el período conocido por los historiadores como "el maximato", ${ }^{10}$ cambió el ritmo de la historia en todos los ámbitos de la vida política y social.

${ }^{10}$ Para enfatizar el predominio político que ejercía el general Plutarco Elías Calles y la debilidad de los presidentes que sucesivamente ocuparon el Poder Ejecutivo después del asesinato del general Obregón en 1928: Emilio Portes Gil, Pascual Ortiz Rubio y Abelardo Rodríguez. 


\section{MARTA GARCÍA UGARTE}

Los enfrentamientos y divisiones militares, tanto en 1920 como en 1923,1927 y 1929 , fueron determinantes para que los presidentes Obregón y Calles recurrieran a la formación de fuerzas armadas no militares que eran reclutadas entre los únicos grupos que entonces estaban dispuestos a "jugar" con el gobierno federal para defender el orden constitucional: los rancheros, peones y medieros del sector rural. De esa manera, la federación, el "Supremo Gobierno" como todavía dicen los hombres del campo, se vio comprometida con los intereses y causas del sector rural popular mientras dejaba de lado los de aquellos que eran los más aptos para gobernar o para llevar a cabo el proyecto que encabezan los sonorenses: la clase media y la aristocracia terrateniente, comercial e industrial.

Esa transformación socio-política que significó el relegamiento de la clase dirigente (aristocracia y profesionistas) del poder y el ascenso de los rancheros, también condicionó el proyecto de desarrollo económico que tenían los sonorenses. En particular el del general Calles, precisamente porque fue durante su administración cuando por los conflictos que se tuvieron que enfrentar - guerra cristera e inestabilidad política generada por el asesinato de Álvaro Obregón en 1928- los rancheros armados alcanzaron mayor fuerza y poder: ellos se convirtieron en uno de los pilares más sólidos del partido naciente, el PNR, y del sistema político que se perfilaba. Como consecuencia, en 1929 el proyecto agrícola para el país diseñado durante el régimen de Obregón y Calles, se trastocó radicalmente en un proyecto agrario. Dicha transformación no pudo realizarse de manera pacífica tanto por la oposición de los propietarios y las demandas de los rancheros como porque los dirigentes nacionales se encontraban divididos: ¿Cuál era la mejor forma de impulsar el desarrollo de la agricultura, actividad fundamental de la nación? De hecho, era el mismo interrogante que se habían formulado los porfiristas en 1902.

Para Calles, la solución al problema de la agricultura estaba en la irrigación y el crédito oportuno, que también eran parte esencial de los planes agrícolas discutidos por el personal de la Secretaría de fomento entre 1902 y 1910 . Por eso se creó la Comisión Nacional de Irrigación para "promover y construir obras de irrigación en la República" el 4 de enero de 1926, y la Ley de Crédito Agrícola publicada el 10 de febrero del mismo año. De manera paralela, se emitió la Ley de Colonización, 
del 5 de abril de 1926, que reglamentaba la fragmentación de las propiedades privadas con excepción de las que tuvieran una adecuada explotación agrícola, aquellas que constituyeran una "unidad agrícola" con tecnología moderna y las que eran cultivadas por una administración directa, es decir, que no recurrían al arrendamiento de los terrenos.

Esas especificaciones delimitaban, de una forma indirecta, que la propiedad agrícola que se tenía en mente era la pequeña propiedad porque ningún latifundio, por su extensión, podía ser trabajado con una administración directa. Así, la Ley de Colonización era un elemento clave en el proyecto de desarrollo agrícola concebido por el general Calles: crear una legión de agricultores, con buenas tierras, modernos, capitalistas, que contaran con una infraestructura para el desarrollo (irrigación, caminos, establos, bodegas) y apoyos institucionales (crédito, tecnología, estímulos fiscales). Era un plan agrícola seria y concienzudamente formulado, que permitiría la expansión económica del sector, la autosuficiencia alimentaria y un mejor balance comercial internacional.

Aún la corriente que fue identificada con el "agrarismo", aquella que buscaba convertir a peones y medieros en agricultores, como pretendía la ley de dotaciones y restituciones de tierras y aguas, publicada durante la administración de Emilio Portes Gil el 21 de marzo de 1929, respetaba la pequeña propiedad: los terrenos que serían afectados para dotar a los solicitantes de tierra serían parte del territorio de las haciendas vecinas y nunca de los ranchos o pequeña propiedad.

Hasta 1929 no había una diferencia notable entre posiciones callista y de Portes Gil, que encabezaba el grupo que se autodefinía como agrarista. No obstante, ya estaban en marcha los dos proyectos para el agro mexicano que se enfrentaran abiertamente durante el cardenismo: el agrícola y el agrario.

\section{Epílogo: breves reflexiones sobre el reparto agrario cardenista}

Como fuerza social en ascenso, la de los rancheros, estaba vinculada por su origen y situación con el proyecto agrario que encabezaba el presidente interino Portes Gil, y fue la corriente que se impuso en medio de una gran violencia en la década de los treinta, el año en que los grupos rancheros de Querétaro lograron unificar sus fuerzas y proponer como 


\section{MARTA GARCÍA UGARTE}

candidato a la gubernatura a uno de sus líderes, el peón de los valles, Saturnino Osornio.

Apoyado por las fuerzas rancheras de la entidad, y por el grupo callista de la capital de la República, Osornio asumió la gubernatura de Querétaro en 1931; no obstante, no estaba interesado en impulsar un proyecto agrario minifundista. Por el contrario, sus esfuerzos se concentraron en conformar una organización sindical rural que obligara a los hacendados a cumplir con las disposiciones laborales del artículo 123 . Sus pretensiones y la eficacia de sus "organizados", más de 10,000 campesinos en la entidad, en escasos cuatro años de gobierno (1931-1935) desestabilizaron los esquemas tradicionales del trabajo agrícola: empezaron a predominar los trabajadores asalariados, sin vínculos afectivos con la hacienda y sin pagos en especie. El latifundio, basado en el trabajador de tarea (los medieros) y en los peones apadronados y acasillados, no podía sobrevivir bajo las nuevas condiciones laborales que demandaban una nueva organización social del trabajo y la propiedad.

Desafortunadamente, los hacendados queretanos no fueron sensibles a los cambios. Su incapacidad para adecuarse a las nuevas formas de producción del proyecto callista determinó la tragedia que vivieron en la década de los treinta, cuando se empantanaron en la defensa de la propiedad que irremediablemente perdían por los adeudos acumulados

46 y no tanto, como ellos aseguraban, por las pretensiones agraristas del gobernador. De hecho, Osornio sólo estimuló el reparto agrario cuando los propios trabajadores planteaban la iniciativa, de manera intensiva al final de su período (1934-1935) para favorecer a los hombres que lo habían acompañado en su gobierno, una vez que fue claro que el presidente Lázaro Cárdenas no estaba dispuesto, por el conflicto con el ex-presidente Calles, en seguir apoyando al grupo osornista de clara filiación callista. Hasta 1935 no se inició el reparto de las haciendas queretanas bajo la forma del ejido que había establecido el Código Agrario de 1934. Es de señalar que el reparto agrario continuó en Querétaro en medio de una gran violencia hasta 1937, cuando el presidente Cárdenas, en un giro todavía no suficientemente investigado, empezó a estimular la expansión de la pequeña propiedad.

Aún cuando habría que hacer una investigación específica, puede considerarse que la emisión del Código Agrario en marzo de 1934, que ordenaba la legislación ejidal, representó cl triunfo de los radicales, que 


\section{PROPUESTA AGRARIA DE VENUSTIANO CARRANZA}

señalaban así su diferencia con el callismo. Sin embargo cabe preguntarse, ¿́acaso la radicalización del reparto agrario durante los primeros años del cardenismo (1934-1937) responde a la composición ideológica del grupo en el poder heredada de la crisis de 1928? ¿Acaso el viraje agrario que se inicia a fines de 1937, cuando se abandona el reparto ejidal y se inicia la defensa de la pequeña propiedad, responde al hecho indudable de la consolidación del poder presidencial de Lázaro Cárdenas?

Es un hecho todavía no suficientemente documentado que Cárdenas retomó, una vez expulsado el ex-presidente Calles del país, el proyecto agrícola que habían encabezado los sonorenses. Ese viraje lleva a preguntarse si en 1937, ya que se habían desmantelado las fuerzas rurales de filiación callista y satisfechos los intereses de los grupos rurales organizados del país que acaban por agruparse en una sola central de clara identidad cardenista, la CNC (Central Nacional Campesina), se podía retomar el proyecto agrícola que del porfiriato al callismo se había querido llevar a cabo en el país.

En suma, las fuerzas triunfantes de la Revolución constitucionalista, carrancistas y sonorenses, asumieron un plan agrícola que permitiera impulsar el desarrollo capitalista de la agricultura mexicana. No obstante, por los compromisos políticos y militares adquiridos con el sector rural que se sumó a las propuestas gubernamentales oficiales, los rancheros, se vieron obligadas a impulsar una reforma agraria moderada que concentraba su atención en la pequeña propiedad. Es claro, al menos para el caso de Querétaro, que la formación del ejido, de escasa extensión, sólo alcanzó difusión en 1929 cuando el futuro de la nación, por los acontecimientos políticos de 1928, se había puesto en entredicho, y en 1934 cuando fue utilizado como un factor de cohesión de las fuerzas rurales que se sumaron al cardenismo.

Así, puede sostenerse que el programa agrario o el esperado fraccionamiento del latifundio que se inició en 1929 , estuvo preñado de una fuerte carga política. De esa manera perdió la importancia estratégica que se le había concedido, desde el porfiriato hasta el gobierno de Plutarco Elías Calles, como parte integral de un proyecto ambicioso de modernización de la actividad agropecuaria. 